\title{
The Use of Indigenous Knowledge in Predicting Changes in Seasonal Rainfall by Smallholder Farmers of Ruteete Subcounty, Kabarole District
}

\author{
Kandida Nyakaisiki', Isaac Mugume ${ }^{2,3}$, Triphonia Ngailo", Rhoda Nakabugo² \\ ${ }^{1}$ Department of Forestry, Biodiversity \& Tourism, Makerere University, Kampala, Uganda \\ ${ }^{2}$ Department of Geography, Geo-Informatics \& Climatic Sciences, Makerere University, Kampala, Uganda \\ ${ }^{3} \mathrm{Hub}$ for Environmental \& Atmospheric Research, Kampala, Uganda \\ ${ }^{4}$ Department of General Studies, Dar es Salaam Technical Institute, Dar es Salaam, Tanzania \\ Email:imugume@caes.mak.ac.ug,imugume@caes.mak.ac.ug
}

How to cite this paper: Nyakaisiki, K., Mugume, I., Ngailo, T., \& Nakabugo, R. (2019). The Use of Indigenous Knowledge in Predicting Changes in Seasonal Rainfall by Smallholder Farmers of Ruteete Subcounty, Kabarole District. Journal of Geoscience and Environment Protection, 7, 13-22.

https://doi.org/10.4236/gep.2019.71002

Received: August 20, 2018

Accepted: January 15, 2019

Published: January 18, 2019

Copyright $\odot 2019$ by author(s) and Scientific Research Publishing Inc. This work is licensed under the Creative Commons Attribution International License (CC BY 4.0).

http://creativecommons.org/licenses/by/4.0/

\begin{abstract}
Climate change has become a serious global challenge. Developing countries are the worst affected due to poor response mechanism to associated disasters. This study examined the application of the indigenous knowledge (IK) methods to predict the changes in seasonal rainfall. The study used data collected through individual interviews using a structured questionnaire. The study found vegetation changes (i.e. shading off leaves, excessive branching); changes in animal behavior (i.e. eating soil, restlessness), and other atmospheric indicators (i.e. changes in wind, color of stars and moon, earthquake, migrating of birds, swarming of bees, cold windy mornings and warm nights) being used to observe and monitor the changes in rainfall over the season. The study recommends a more detailed study to validate the IK and integrate it with the scientific knowledge so as to reduce local farmers' vulnerability, increase resilience and strengthen their adaptive capacity to cope with climate change effects.
\end{abstract}

\section{Keywords}

Indigenous Knowledge, Predictors of Seasonal Rainfall, Climate Change Adaptation, Indicators of Changes in Climate

\section{Introduction}

The global climate is changing due to anthropogenic factors which are contri- 
buting to greenhouse gases in the atmosphere (Kpadonou et al., 2012; Ziervogel \& Opere, 2010). This has impacted the local people in a number of ways such as increased temperatures, floods and hail-storms which have all reduced productivity of the agricultural and forestry sector rendering the communities vulnerable to the impacts of climate change (Forzieri et al., 2018; Mugume et al., 2017). However the vulnerability to these impacts depends on ecological and socioeconomic characteristics of each community (Forzieri et al., 2018; Tao et al., 2016), and they occur unevenly in different places due to the differences in geographical location and the natural resources of each area (Kpadonou et al., 2012; Gyampoh et al., 2009).

The efforts addressing global warming have concentrated on measures such as repair and restore of the environment after damage and compensatory measures done with the aim of reducing and possibly stabilizing the greenhouse gas concentrations in the atmosphere (Twagiramaria et al., 2017; Berkes, 2009). One approach is adaption and this refers to the response to climate change that seeks to reduce the vulnerability of social and biological systems to climate change effects (Zhang \& Nakagawa, 2018; Tao et al., 2016). It involves adjustments in behavior or economic structures to reduce the vulnerability of a society to the effects of climate change and often strengthen its capacity to benefit from those effects (Tao et al., 2016; Gyampoh et al., 2009).

In Uganda, different adaptation measures have been used to reduce the impacts of climate change, including irrigation, crop rotation, water harvesting, mulching and many others (Twagiramaria et al., 2017; Otto-Banaszak et al., 2011). Because of these differences, some communities are more exposed and more sensitive to the adverse effects of climate change than others (Kpadonou et al., 2012; Forzieri et al., 2018). For example, communities living in areas such as lake shores, river banks steep slopes of mountains are more vulnerable to climate change impacts such as floods and landslides than communities on gentle slopes (Warwick et al., 2018; Bathi \& Das, 2016).

In order to reduce the community's vulnerability to the impacts of climate change, the local people are using indigenous knowledge about their environment and are implementing various adaptation measures such as maintaining genetic and species diversity (Tao et al., 2016); others plant quick and improved maturing species (Twagiramaria et al., 2017); some farmers use traditions e.g. the taboos (Nyong et al., 2007). All these and many others help them to cope with climate related risks such as floods and droughts (Zhang \& Nakagawa, 2018; Ramos-Castillo et al., 2017; Otto-Banaszak et al., 2011; Nyong et al., 2007). Indigenous knowledge is believed to have the potential of increasing resilience to current and future climatic events (Zhang \& Nakagawa, 2018; Hadgu \& Gebremichael, 2013). One way of enhancing the resilience is improved rainfall prediction. Ziervogel \& Opere (2010) suggested the integration of conventional and traditional prediction systems to improve rainfall prediction. This study examines the indigenous skills used in predicting uncertain seasonal rainfall by the farmers of Ruteete sub-county. 


\section{Study Area}

This study was conducted in Ruteete sub-county (Figure 1), located in Burahya county, Kabarole district, western Uganda. Ruteete is bordered by Busooro sub-county in the North, Buheesi sub-county in the East, Rwimi sub-county in the South East, Kibiito subcounty and Kyenjojo district, with a greater part covered by Kibale forest (Sezi, 2014; Berkhoudt, 2012). Ruteete sub-county lies between $0^{\circ} 15^{\prime} \mathrm{N}$ and $1^{\circ} 00^{\prime} \mathrm{N}$ latitudes and $30^{\circ} 00^{\prime} \mathrm{E}$ to $31^{\circ} 15^{\prime} \mathrm{E}$ longitudes and altitude of 1420 - $1550 \mathrm{~m}$ above mean sea level (Sezi, 2014). The study used two locations namely, Kiko trading center, the chief town of the subcounty and Kyamukoka.

\subsection{The Climate of the Study Area}

This sub-county has favorable climate with well distributed rainfall throughout the year. The rainfall is bimodal ranging from $1200-1500 \mathrm{~mm}$ per season and

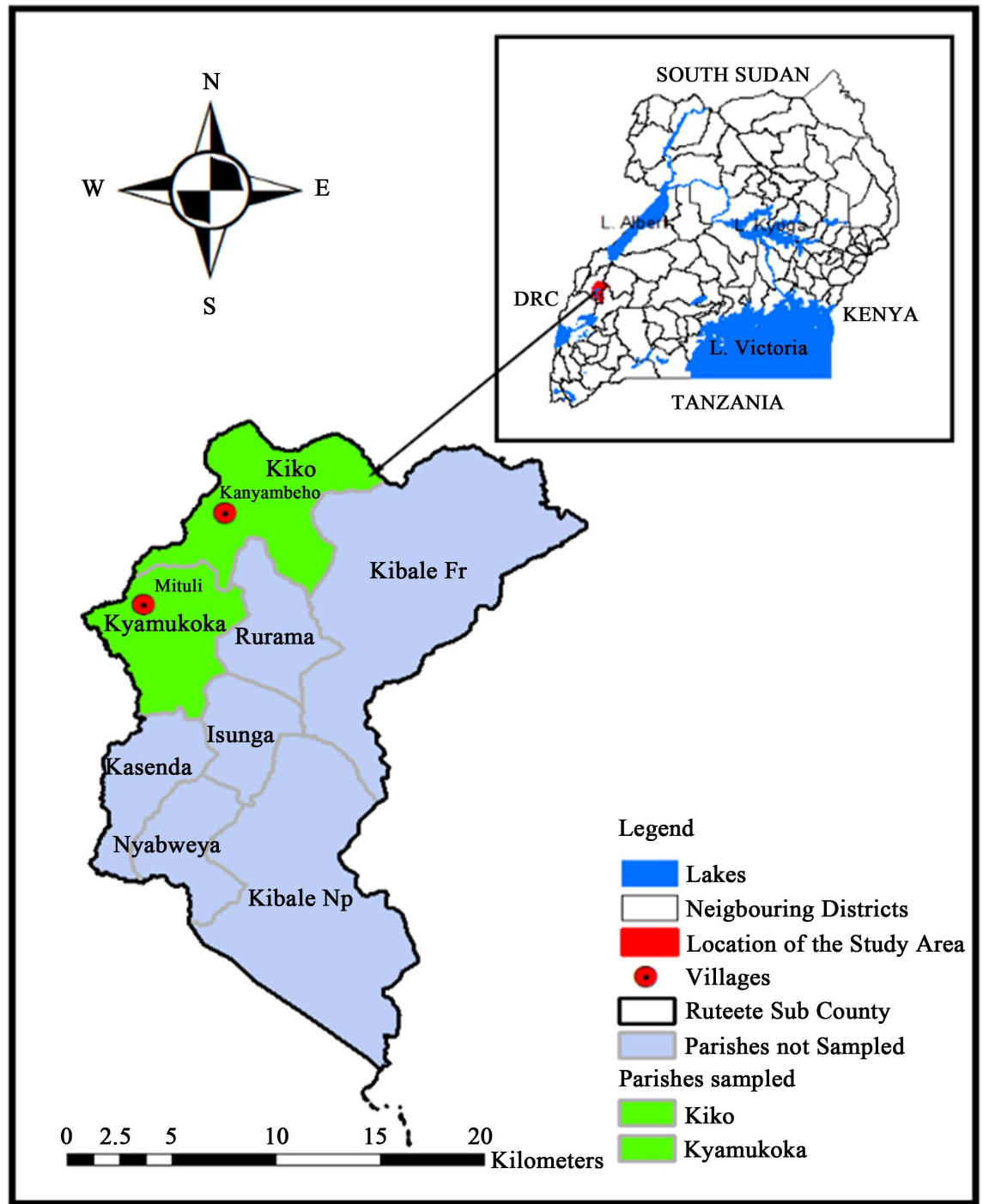

Figure 1. The study area. Inset is the map of Uganda showing the study location. 
average temperatures ranging $20^{\circ} \mathrm{C}-25^{\circ} \mathrm{C}$ that are favorable for agriculture in the area.

Like other areas, Ruteete sub-county is also facing the problem of changing climate and weather patterns which has manifested as, e.g. increased flooding of nearby rivers especially in the wet season causing disruptions in transport, outbreak of pests and diseases; prolonged dry seasons that lower crop yields among other effects.

\subsection{Socio-Economic and Demographic Characteristics of the Study Area}

The people in Ruteete sub-county are majorly small-holder farmers and grow crops such as maize, finger millet, bananas, cassava, potatoes and many others (Isingoma, 2017). In spite of the challenges faced by farmers due to changing climate, this sub-county, was ranked among the first five top food producing areas in Kabarole district (i.e. Rwimi, Kisomoro, Karambi, Hakibale and Ruteete respectively) (Kisakye et al., 2018; Berkhoudt, 2012), a probable indicator that farmers are employing relevant adaptation measures to manage the adverse impacts of climate change. Additionally, the tea companies e.g. Kiko tea estates and other tea out-growers carryout commercial tea growing on large-scale.

This sub-county is also blessed with tourism activities namely, the nature walk, recreation within the Kibale National park and the surrounding volcanic lakes in Kasiiso, Rwenkuba and Rwihamba (Berkhoudt, 2012). Other business activities carried out include the retail business, hotel and hospitality business and many other informal business in the trading centers of Kiko, Kanyambeho, Mituli and many other centers.

\subsection{Soils and Vegetation}

Ruteete sub-county has a gentle sloping landscape with hills rolling towards the Kanyawara wet-lands, Njuguta and Rwibitaba (Berkhoudt, 2012). These wetlands are the major sources of water during the dry season. The subcounty also has volcanic crater lakes namely, Nyabinamba and Nyamwihura in Rwenkuba and Kasiiso villages respectively, which are mainly at the footsteps of the gently rolling hills. This sub-county is mainly covered by black loams over red sandy clay loams e.g. Rwetera Rwihamba and Nkuruba. In most areas of the sub-county, the red sandy loams are covered by soft laterites. The vegetation is mainly savannah, with humid tropical forests such as Kibale national park and elephant grasses.

\section{Study Materials}

\subsection{Study Design}

This study was based on the primary data collected from the sub-county. It was carried out using cross-sectional study design (Isingoma, 2017; Levin, 2006) and collected both quantitative and qualitative data (Isingoma, 2017) by administer- 
ing questionnaire. The study involved the use of structured questions that were distributed randomly to the selected household respondents. The cross-sectional design is one where data is collected at a given point or over a short period (Levin, 2006) and the data collected was analyzed using descriptive statistics including using percentages. This study used the cross-sectional study design because it considered that, the responses from people are time-invariant and data collection was carried out over the period of March 2018.

Ruteete sub-county has seven parishes which include Isunga, Kasenda, Kyamukoka, Nyabweya, Rurama, Kiko and Kibale National Park (Berkhoudt, 2012). This study was carried out in 2 parishes namely, Kiko and Kyamukoka which were chosen purposively because they are the major food producers of the sub-county (Kisakye et al., 2018). From the two chosen parishes, one village from each parish was again chosen purposively i.e. Kanyambeho A and Mituli respectively to represent the whole parish and this was because of their accessibility.

The sampling framework was obtained from the local council chairperson of the village which was used as a guide to choose the respondents. Simple random sampling was used and 30 farmers from each village were chosen randomly who provided the necessary information for the study in that particular village and this study used a total of 60 respondents to represent the whole sub-county.

\subsection{Data Collection Methods}

The study collected data about: the plant predictors; the animal predictors; and the atmospheric predictors used by the small-holder farmers over the study area for monitoring and predicting the rainfall seasons. The data was collected by interviewing using a structured questionnaire and included the main guiding questions were:

1) What is/are your source(s) of income?

2) Do you believe that climate has changed?

3) What do you use to monitor changes in atmosphere, for indicating seasons?

\subsection{Data Analysis}

This study used descriptive statistics i.e. the percentages, frequency tables and graphs to organize and summarize the data about the indigenous predictors used by the small-holder farmers to predict rainfall seasons. Cross tables are used to present the results for the different ways of monitoring and observing changes in the atmosphere and their corresponding expected weather changes.

\section{Results}

The different ways of predicting changes in the atmosphere by small-holder farmers is presented in the sections following i.e. the plant predictors (Section 4.1); the animal predictors (Section 4.2) and the atmospheric predictors (Section 4.3). 


\subsection{Plant Predictors}

Figure 2 shows the changes in the phenology of plants which are used by the small-holder farmers over the study area as predictors of changes in the rainfall season. The respondents observe plant species namely, Erythrinaabyssinica and most of theFicus species e.g. the Ficusovata and Ficusnatalensis.

This study found that of the responds $5.9 \%$ consider the shading off of the tree leaves for an approaching rainfall season yet $73.5 \%$ considered it to signify rainfall cessation and approaching of the dry season.

Additionally, $32.4 \%$ of the smallholder farmers considered excessive branching of sweet potatoes vines to signify onset of the rain season which was refuted by $5.8 \%$ who claimed that it signify the rainfall cessation and thus a dry season setting in. They also observe the Omujumbajumba" which normally shades off all its leaves towards the rain season and sprouts again as soon as the rains begin.

A study by Jiri et al. (2015) noted the use plant and tree phenology to predict weather changes e.g. the disappearance and delayed fruiting of trees such as Maroro indicated a long drought period in Zimbabwe. Another study by Luo (2016) on the Tibetan plateau noted that some grass species e.g. the bog sedge can tell an approaching Indian monsoon and go into self-defense mode. For our study, the farmers considered the shading off of leaves Erythrinaabyssinica, Ficusovata and Ficusnatalensis normally indicates a dry season. This suggests that if we can consistently monitor the changes in plant characteristics, we can improve the prediction of weather and climate.

\subsection{Animal Predictors}

For using changes in animal behaviors, the study found that the farmers use restlessness of animals (88.2\%) to mean the onset of the rainfall season and eating of the soil (29.4\%) to indicate rainfall cessation. A similar study by Okonya \& Kroschel (2013) also noted that when animals become restless, it is a sign of the onset of the rainy season.

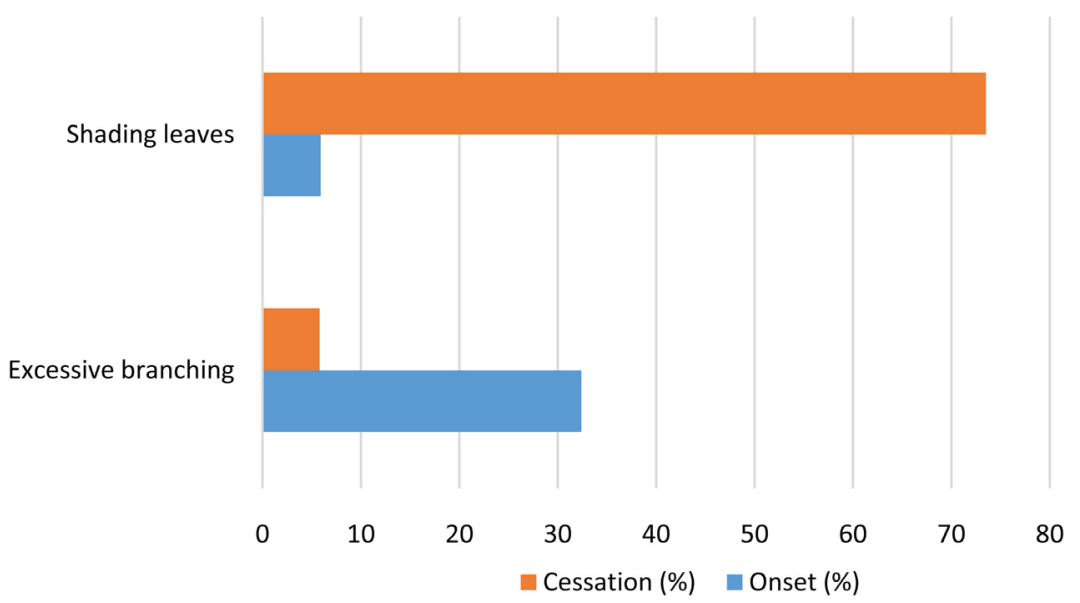

Figure 2. Shows the plant predictors used by small-holder farmers in Ruteete sub-county to predict changes in season. 
The use of changes in animal behavior to predict weather is also recognized by Alves \& Barboza (2018) who referred to animals as Ethnozooindicators. They argued that many species of the vertebrates and invertebrates are very sensitive to changes in weather and this is directly observed in the physiological and reproductive characteristics they exhibit when weather changes.

\subsection{Atmospheric Predictors}

Table 1 shows the percentage of respondents using atmospheric predictors to predict the onset and cessation of rain season and dry season. Analysis of results presented in Table 1 shows that the three predictors mostly used by farmers are: 1) changes in wind direction (onset: $64.7 \%$ \& cessation: $47.1 \%$ ); 2) star and moon becoming red (onset: $31.4 \%$ \& cessation: $72.5 \%$ ) and 3) migrating birds (onset: $27.5 \%$ \& cessation: $56.9 \%$ ). Further analysis shows that the farmers probably attach different importance to different predictors. For examples whereas most of the farmers relied on the changing of wind direction to signify onset (i.e. $64.7 \%$ ) only $47.1 \%$ used it to signify cessation compared to $72.5 \%$ who used red stars and moon to signify cessation.

A study by Jiri et al. (2015) found local farmers in South Africa using the changes in wind direction as a predictor of seasonal changes. A similar study by and Orlove et al., (2010) over Southern Uganda also found the same.

\section{Summary and Conclusion}

This study aimed at identifying the seasonal rainfall predictors used by small holder farmers in Ruteete sub-county and interviewed a total of 60 respondents. The study found the farmers using plant and animal indicators along with other atmospheric indicators to predict the onset and cessation of rainfall.

The findings show that the farmers used shading off of leaves and excessive branching of sweet potatoes vines to signify changing of season. They also use restlessness and grazing of domestic animals on soil as a predictor of changing season. Additionally the farmers use changes in the atmosphere to also indicate

Table 1. Shows the atmospheric predictors for the rainy season.

\begin{tabular}{ccc}
\hline \multirow{2}{*}{ Predictors } & \multicolumn{2}{c}{ Rain season } \\
\cline { 2 - 3 } & On-set (\%) & Cessation $(\%)$ \\
\hline Cold windy mornings & 5.9 & 17.6 \\
Red stars and moon & 31.4 & 72.5 \\
Earthquake & 27.5 & 15.7 \\
Swarming bees & 9.8 & 29.4 \\
Migrating birds e.g. swallows & 27.5 & 56.9 \\
Reducing morning dew & 21.5 & 27.5 \\
Changes in wind direction & 64.7 & 47.1 \\
Warm nights & 13.7 & 33.3 \\
\hline
\end{tabular}


changes in the season. However, the study also found that farmers attached different importance to different predictors in predicting onset and cessation of rainfall.

Thus, indigenous ways can help in observing and monitoring changes in the atmosphere. This study found that farmers have extensive knowledge which they use to predict the environmental changes, including changes in climate and weather. The respondents normally relied on a number of signs to predict seasonal changes and other climate variability. Due to varied opinions of the respondents, there is need to harmonize the predictors and evaluate the skill of the indigenous predictors.

\section{Acknowledgements}

We thank the Editor and the referee for their comments. The authors are further grateful to the respondents who provided their valuable time and responses that made the study a success. We're also grateful to Mr. Bwango Herbert Atwooki who funded the data collection exercise and to the WIMEA-ICT project (UGA-13/00018) for the financial support to publish this work.

\section{Conflicts of Interest}

The authors declare no conflicts of interest regarding the publication of this paper.

\section{References}

Alves, R. R. N., \& Barboza, R. R. D. (2018). Animals as Ethnozooindicators of Weather and Climate. In Ethnozoology (pp. 383-420). https://doi.org/10.1016/B978-0-12-809913-1.00021-1

Bathi, J. R., \& Das, H. S. (2016). Vulnerability of Coastal Communities from Storm Surge and Flood Disasters. International Journal of Environmental Research and Public Health, 13, 239. https://doi.org/10.3390/ijerph13020239

Berkes, F. (2009). Indigenous Ways of Knowing and the Study of Environmental Change. Journal of the Royal Society of New Zealand, 39, 151-156. https://doi.org/10.1080/03014220909510568

Berkhoudt, K. (2012). Moral Natures: The Convergence of Imagined Futures around a National Park in Uganda. Doctoral Dissertation, University of Illinois at Urbana-Champaign.

Forzieri, G., Bianchi, A., e Silva, F. B., Herrera, M. A. M., Leblois, A., Lavalle, C., et al. (2018). Escalating Impacts of Climate Extremes on Critical Infrastructures in Europe. Global Environmental Change, 48, 97-107. https://doi.org/10.1016/j.gloenvcha.2017.11.007

Gyampoh, B. A., Amisah, S., Idinoba, M., \& Nkem, J. (2009). Using Traditional Knowledge to Cope with Climate Change in Rural Ghana. Unasylva, 60, 70-74.

Hadgu, K. M., \& Gebremichael, D. (2013). Indigenous Knowledge Practices for Climate Change Adaptation and Impact Mitigation: The Case of Smallholder Farmers in Tigray, Northern Ethiopia.

Isingoma, F. (2017). Coping with the Conflicts between Agriculture and Biodiversity Conservation in Kiko Town Council in the Western Parts of Kibale National Park, Ka- 
barole District. Bishop Stuart University Repository.

Jiri, O., Mafongoya, P. L., \& Chivenge, P. (2015). Indigenous Knowledge Systems, Seasonal "Quality" and Climate Change Adaptation in Zimbabwe. Climate Research, 66, 103-111. https://doi.org/10.3354/cr01334

Kisakye, V., Akurut, M., \& Van der Bruggen, B. (2018). Effect of Climate Change on Reliability of Rainwater Harvesting Systems for Kabarole District, Uganda. Water, 10, 71. https://doi.org/10.3390/w10010071

Kpadonou, R. A., Adégbola, P. Y., \& Tovignan, S. D. (2012). Local Knowledge and Adaptation to Climate Change in Ouémé Valley, Benin. African Crop Science Journal, 20, 181-192.

Levin, K. A. (2006). Study Design III: Cross-Sectional Studies. Evidence-Based Dentistry, 7, 24-26. https://www.nature.com/articles/6400375 https://doi.org/10.1038/sj.ebd.6400375

Luo, T. (2016). Plants That Can Predict the Weather? Scientists Find Them in Tibet and They May Have Evolved to Withstand Climate Change. South China Morning Post: Science \& Research.

Mugume, I., Basalirwa, C. P. K., Waiswa, D., \& Ngailo, T. (2017). Spatial Variation of WRF Model Rainfall Prediction over Uganda. JEnviron Chem Ecol Geol Geophys Eng, 11, 553-557.

Nyong, A., Adesina, F., \& Elasha, B. O. (2007). The Value of Indigenous Knowledge in Climate Change Mitigation and Adaptation Strategies in the African Sahel. Mitigation and Adaptation Strategies for Global Change, 12, 787-797.

https://doi.org/10.1007/s11027-007-9099-0

Okonya, J. S., \& Kroschel, J. (2013). Indigenous Knowledge of Seasonal Weather Forecasting: A Case Study in Six Regions of Uganda. Agricultural Sciences, 4, 641. https://doi.org/10.4236/as.2013.412086

Otto-Banaszak, I., Matczak, P., Wesseler, J., \& Wechsung, F. (2011). Different Perceptions of Adaptation to Climate Change: A Mental Model Approach Applied to the Evidence from Expert Interviews. Regional Environmental Change, 11, 217-228.

https://doi.org/10.1007/s10113-010-0144-2

Ramos-Castillo, A., Castellanos, E. J., \& McLean, K. G. (2017). Indigenous Peoples, Local Communities and Climate Change Mitigation. Climatic Change, 140, 1-4. https://doi.org/10.1007/s10584-016-1873-0

Sezi, C. L. (2014). The Phenomenon of Diminishing-Returns in the Use of Bed Nets and Indoor House Spraying and the Emerging Place of Antimalarial Medicines in the Control of Malaria in Uganda. African Health Sciences, 14, 100-110.

https://doi.org/10.4314/ahs.v14i1.16

Tao, S., Shen, S., Li, Y., Wang, Q., Gao, P., \& Mugume, I. (2016). Projected Crop Production under Regional Climate Change Using Scenario Data and Modeling: Sensitivity to Chosen Sowing Date and Cultivar. Sustainability, 8, 214.

https://doi.org/10.3390/su8030214

Twagiramaria, F., Tolo, C. U., \& Zinyengere, N. (2017). Adaptation to and Coping Strategies for Climate Change and Variability by Rural Farmers in Kigezi Highlands, Uganda. In Beyond Agricultural Impacts (pp. 55-75). Amsterdam, Netherlands: Elsevier.

Warwick, R. M., Tweedley, J. R., \& Potter, I. C. (2018). Microtidal Estuaries Warrant Special Management Measures That Recognise Their Critical Vulnerability to Pollution and Climate Change. Marine Pollution Bulletin, 135, 41-46.

https://doi.org/10.1016/j.marpolbul.2018.06.062 
Zhang, H., \& Nakagawa, H. (2018). Validation of Indigenous Knowledge for Disaster Resilience against River Flooding and Bank Erosion. In Science and Technology in Disaster Risk Reduction in Asia (pp. 57-76). Cambridge: Academic Press. https://doi.org/10.1016/B978-0-12-812711-7.00005-5

Ziervogel, G., \& Opere, A. (2010). Integrating Meteorological and Indigenous Knowledge-Based Seasonal Climate Forecasts for the Agricultural Sector: Lessons from Participatory Action Research in Sub-Saharan Africa (p. 1). CCAA Learning Paper. 